\title{
Feasibility and potential acceptability of three cervical barriers among vulnerable young women in Zimbabwe
}

\author{
Ariane van der Straten, Nuriye Sahin-Hodoglugil, Kate Clouse, Sibongile Mtetwa, Mike Z Chirenje
}

\begin{abstract}
Background We explored the potential acceptability of three cervical barriers (CB) (Ortho All-Flex ${ }^{\circledR}$ diaphragm, SILCS ${ }^{\circledR}$ diaphragm, FemCap ${ }^{T M}$ cervical cap) among sexually experienced Zimbabwean young women.

Methods Forty-five young women (aged 16-21 years) received an individual $\mathrm{CB}$ educational session. Participants were then randomly assigned to one of the three $\mathrm{CBs}$ in a 1:1:1 ratio, and practised insertion and removal of their device at the clinic. Next, participants were interviewed on their practice experiences, and their post-practice attitudes towards CB.
\end{abstract}

Results All 45 young women were willing and able to insert their assigned device. The majority reported "easy" insertion and removal and 93\% "liked" the device they tried. All showed interest in participating in future CB studies: when asked which device they would like to try in the future, over half $(58 \%)$ chose SILCS, regardless of the device they had tried. The majority felt comfortable touching their genitals to insert/remove the $C B$ and most participants favoured methods' attributes associated with female-control and non-interference with sex. Over half the participants said they would prefer to use a CB continuously compared to episodic use. Two-thirds of them expressed interest in $C B$ for dual protection.

Conclusion The concept of $\mathrm{CB}$, and initial insertion experience, were well accepted in this selected, small group of Zimbabwean young women. Evaluating $\mathrm{CB}$ in larger studies seems feasible in this population.

Keywords acceptability, cervical barrier method, contraception, HIV prevention, young women

J Fam Plann Reprod Health Care 2010; 36(1): 13-19 (Accepted 22 September 2009)

\section{Introduction}

Young women are the most vulnerable population for heterosexual acquisition of HIV. ${ }^{1}$ Adolescents are more susceptible than adult women, likely because an immature genital tract increases their susceptibility to physical trauma and sexually transmitted infections (STIs). ${ }^{2}$ Furthermore, gender inequalities in sexual relationships often leave young women unable to negotiate condom use. ${ }^{3-5}$ In Zimbabwe, $25 \%$ of females aged 15-24 years are infected with HIV compared to $11 \%$ of males in that age group. 6 Additionally, with $40 \%$ of Zimbabwean women aged 15-49 years being non-current users of modern family planning methods, there remains a significant unmet need for contraception, particularly among young sexually active women (63\% non-current users among 15-19-yearolds), as indicated by estimates that up to $60000-80000$ illegal and unsafe abortions occur each year. 6,7

Male condoms are the only currently available method known to provide dual protection by preventing pregnancy

Women's Global Health Imperative, RTI International, San Francisco, and Center for AIDS Prevention Studies, Department of Medicine, University of California San Francisco, San Francisco, CA, USA

Ariane van der Straten, PhD, MPH, Senior Research Scientist

Venture Strategies for Health and Development, Berkeley, CA, USA

Nuriye Sahin-Hodoglugil, MD, DrPH, Associate Medical Director

University of North Carolina at Chapel Hill, Gillings School of Global Public Health, Department of Epidemiology, Chapel Hill, NC, USA

Kate Clouse, MPH, PhD Graduate Student

University of Zimbabwe-University of California San Francisco Collaborative Research Programme in Women's Health, Harare, Zimbabwe

Sibongile Mtetwa, BA, Project Co-ordinator

Mike Z Chirenje, MD, FCROG, Associate Professor and Executive Director

Correspondence to: Dr Ariane van der Straten, Senior Research Scientist, 114 Sansome Street, Suite 500, San Francisco, CA 94104, USA. E-mail: ariane@rti.org

\section{Key message points}

- Diaphragm-naive Zimbabwean young women willing and able to correctly insert one of three randomly assigned cervical barriers (CB) in a clinical setting, and the majority reported the experience as "easy".

- A majority was interested in $\mathrm{CB}$ for dual protection (against disease and pregnancy).

- Over half the young women in all three groups said they wanted to try the SILCS ${ }^{\circledR}$ diaphragm in the future.

and STIs including HIV; although not proven in clinical trials, female condoms are believed to provide similar protection. ${ }^{8,9}$ While female condoms are woman-initiated, they still require male partner co-operation, as they are noticeable during sex. Cervical barriers (CB), including the diaphragm, are also woman-initiated methods, and act by protecting the cervix from exposure to ejaculate. The diaphragm is one of the oldest contraceptives, although it has lost much of its popularity with the advent of hormonal contraceptives. ${ }^{10} \mathrm{CB}$ might be of interest to women who prefer a non-hormonal method or who have experienced side effects with hormonal methods. CB have the potential to provide dual protection because they cover the cervix, a 'hot spot' for some STIs and HIV, leading to a renewed interest in these methods, ${ }^{11,12}$ and ongoing research on the diaphragm's possible role for HIV or STI prevention. ${ }^{13-16}$ This effort continues, despite disappointing results from a recently completed trial of the diaphragm used with a lubricant gel, the MIRA trial, which was unable to demonstrate a protective effect of the intervention against HIV or cervical STIs, over and above that of male condoms. ${ }^{17-19}$ Nevertheless, it is still biologically plausible that the diaphragm or other $\mathrm{CB}$ can provide partial protection from cervical infections, and function as a reusable delivery mechanism for, or enhance the effectiveness of, a microbicidal gel. ${ }^{20}$ Indeed, as $\mathrm{CB}$ retain gel close to the cervix, they may potentially prolong the duration of action of a microbicide in situ, by slowing the rapid leakage of gel to the lower vagina and the introitus during sexual intercourse. ${ }^{21}$

Recently, new CB devices with improved designs have 
been developed, which do not require fitting, come in one or only a few sizes, and harbour special features for insertion and removal, potentially simplifying method access and use. Among these new devices are the FemCap $^{\mathrm{TM}}$ cervical cap and SILCS ${ }^{\circledR}$ diaphragm, both made of medical-grade silicone, which is less allergenic, more durable, and more tolerant of heat, light and petroleum products than the latex diaphragm. In the USA, contraceptive trials have been conducted or are ongoing for these new devices, ${ }^{22-25}$ and acceptability studies have been conducted internationally, primarily in adult women or women in stable monogamous relationship, for the diaphragm ${ }^{14,15,26-29}$ and for SILCS. ${ }^{30,31}$ Although product acceptance has been high in these studies, findings cannot be extrapolated to younger, or unmarried, women whose choices and acceptability differ for other contraceptive and disease prevention methods. ${ }^{32-35}$

This study focused on young women, a vulnerable population in Zimbabwe, with the purpose of assessing the feasibility and potential acceptability of three $\mathrm{CB}$, the Ortho All-Flex ${ }^{\circledR}$ diaphragm, the FemCap cervical cap and the SILCS diaphragm, as potential disease prevention and contraceptive methods.

\section{Methods}

\section{Study design and participants}

This was a mixed methods exploratory study with two interrelated components: the first qualitative and the second clinical. For the first component, focus group discussions (FGDs) were conducted with young women and with adult women (who were mothers and aunts of the former) on sociocultural issues around sex, reproductive health, knowledge about HIV prevention, and to discuss CB methods. During the FGDs, participants were presented with three different $\mathrm{CB}$ and each was demonstrated using a pelvic model. Attitudes about, and reactions to, the devices were collected. Qualitative data from these FGDs are presented elsewhere. ${ }^{36}$

For the second (i.e. clinical) study component, young women who participated in the FGDs were invited back 2 weeks later, to practise inserting and removing one of the three randomly assigned $\mathrm{CB}$ in the clinic under the supervision of a clinician, They were then interviewed on their practice experiences, along with their post-practice attitudes towards CB. The results of this second component are reported here.

This study was conducted concurrently with the MIRA $\operatorname{trial}^{18}$, between May and September 2006; a total of 93 young women aged 16-21 years were approached and prescreened by outreach workers in schools, youth centres, sports clubs, youth-friendly clinics, and market places in the city of Chitungwiza, near Harare. Fifty-one (55\%) young women came to the study site and were re-screened for eligibility. Of those, 47 were eligible, and completed a FGD. Eligibility criteria included being aged 16-21 years, ever having had vaginal sex, living in the greater Harare region, being able to read, write and speak English or Shona (the local language), and willing and able to give written informed consent. Forty-five $(96 \%)$ young women returned for one follow-up clinical visit 2 weeks after their FGD and these individuals constitute our analytical sample. Two women withdrew prior to the follow-up visit (one moved to Botswana and one started working full time).

\section{Study procedures}

A female study clinician presented the three study $\mathrm{CB}$ and provided each participant with a standardised educational overview: briefly, participants were told that $\mathrm{CB}$ can

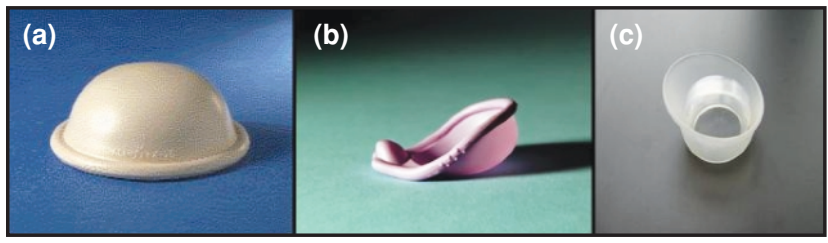

Figure 1 The three cervical barriers (CB) employed in the study. (a) Ortho All-Flex ${ }^{\circledR}$ (Ortho-McNeil, Inc., Titusville, NJ, USA) is a peach, dome-shaped, latex rubber cup with a flexible rim. Worldwide, it is the most available CB. It comes in nine sizes (ranging from 55 to $95 \mathrm{~mm}$, in $5 \mathrm{~mm}$ increments) and must be fitted by a clinician. It is US Food and Drug Administration (FDA) approved for contraception when used with a contraceptive gel, which can be loaded onto the cervical side (within the cup) prior to insertion.

(b) SILCS ${ }^{\circledR}$ (PATH, Seattle, WA, USA) is a purple, dome-shaped silicone diaphragm. It has an anatomically shaped, contoured design for easy placement and removal. It is a "one-size-fits-most" device and requires no fitting. It is not yet FDA approved, but is being evaluated in a Phase II/III contraceptive effectiveness trial. 25 Gel can be loaded on the cervical and vaginal sides of the device prior to insertion.

(c) FemCap ${ }^{\mathrm{TM}}$ (FemCap Inc., Del Mar, CA, USA) is a domeshaped, white silicone device with a wide brim. It is designed to conform to the shape of the vaginal fornices and cervix. The brim is designed to hold gel and trap sperm. There is a removal strap over the dome. It comes in three sizes, as determined by obstetric history, so no clinician fitting is required. It is FDA approved for contraception when used with a contraceptive gel. Gel can be loaded on the cervical and vaginal sides of the device prior to insertion.

prevent pregnancy when used with a contraceptive gel, that they have the potential to provide some protection against STIs, and that the diaphragm was currently being evaluated for HIV/STI prevention. The three devices were handed to the participants, who were encouraged to examine their shape and feel, and were shown how they are worn inside the vagina, as demonstrated on a translucent pelvic model. The clinician then pointed to each $\mathrm{CB}$ (in random order) and explained its fitting and sizing requirements (Figure 1).

After the educational session, participants were given the choice to opt out of the practice session but none of them declined. All 45 participants were randomly assigned to one of the three $\mathrm{CB}$, after opening sequentially numbered, sealed, opaque envelopes: 14 were assigned to SILCS, 15 to Ortho All-Flex and 16 to FemCap. The participants assigned to Ortho All-Flex were fitted for the device by the clinician (median size $70 \mathrm{~mm}$, range 60-75 $\mathrm{mm}$ ). For those assigned to FemCap, seven used a size 22 $\mathrm{mm}$ and nine a size $26 \mathrm{~mm}$ based on their obstetric history. Each participant was given K-Y ${ }^{\circledR}$ Jelly Personal Lubricant (Personal Products Company, Skillman, NJ, USA) to spread onto the rim of her device to facilitate insertion, and practised insertion and removal under the guidance of the study clinician. The clinician also conducted an assessment of the insertion and removal process and placement of the device in situ, and reported how many attempts were needed before correct insertion of the device.

\section{Measures and analysis}

Prior to the FGD, all participants completed a brief selfadministered demographic form. At the follow-up visit, each participant completed an additional background and demographic questionnaire administered in private by a trained female interviewer. For the $\mathrm{CB}$ practice session, the clinician collected device fitting information, insertion and removal data on a study form. Finally, a trained interviewer conducted a follow-up interview using a structured interview guide with close- and open-ended questions to assess each participant's experiences with insertion and removal of their device, along with their post-practice 
Table 1 Characteristics of the study participants $(n=45)$

\begin{tabular}{|c|c|c|}
\hline Characteristic & $n$ & $\%$ \\
\hline Median age (range) & $19(16-21)$ & \\
\hline Median years of education (range) & $11(4-13)$ & \\
\hline $\begin{array}{l}\text { Median total lifetime sexual partners } \\
\text { (range) }\end{array}$ & $1 \quad(1-10)$ & \\
\hline Median age at first sex (range) & $17(13-20)$ & \\
\hline \multicolumn{3}{|l|}{ Lifetime frequency of sex } \\
\hline Rarely or occasionally & 24 & 53.3 \\
\hline Regularly & 21 & 46.7 \\
\hline Has a husband or regular partner & 33 & 73.3 \\
\hline \multicolumn{3}{|l|}{ Marital status } \\
\hline Married & 24 & 53.3 \\
\hline Single & 13 & 28.9 \\
\hline Divorced or widowed & 8 & 13.3 \\
\hline Has children & 26 & 57.8 \\
\hline Earned income in the past year & 17 & 37.8 \\
\hline "Very worried" about getting pregnant & 32 & 71.1 \\
\hline "Very worried" about getting HIV & 39 & 84.4 \\
\hline $\begin{array}{l}\text { Intravaginally inserted products a in } \\
\text { past year }\end{array}$ & 30 & 66.7 \\
\hline Washes intravaginally with fingerb & 38 & 84.5 \\
\hline Ever touched her cervix & 18 & 40.0 \\
\hline Ever heard of the diaphragm & 13 & 28.9 \\
\hline Ever used the diaphragm & 0 & 0.0 \\
\hline \multicolumn{3}{|l|}{ Current contraceptive method } \\
\hline No method & 13 & 28.9 \\
\hline Pills & 16 & 35.6 \\
\hline Male condoms & 8 & 17.8 \\
\hline Injectables or Norplant ${ }^{\circledR}$ & 5 & 11.1 \\
\hline Multiple methods (hormonal + condoms) & 2 & 4.4 \\
\hline Rhythm & 1 & 2.2 \\
\hline \multicolumn{3}{|l|}{ Frequency of condom use during sex } \\
\hline Every time & 11 & 24.4 \\
\hline Sometimes & 22 & 48.9 \\
\hline Never & 12 & 26.7 \\
\hline
\end{tabular}

aproducts reported were: tampons, cotton wool, cloth, female condoms, herbs, other.

bReported washing regularly $(n=31)$ or occasionally $(n=7)$ with water $(n=31)$ or water and soap $(n=7)$. attitudes about $\mathrm{CB}$. These attitudes were assessed using a 15-item questionnaire derived from two validated barrier method self-efficacy instruments 37,38 with Likert-type responses (strongly agree, agree, disagree, strongly disagree; collapsed into two categories for this analysis: agree vs disagree).

Quantitative data were summarised using frequency tables for categorical variables, medians and ranges for continuous variables, using STATA ${ }^{\mathrm{TM}}$ (Version 10.0, StataCorp, College Station, TX, USA). Number of attempts prior to successful insertion, experience about device insertion/removal, and attitudes and preferences about the devices were tabulated and presented both overall and separately for each device group. This was a pilot exploratory study with a small sample size; no statistical tests were performed and only descriptive analyses were conducted. Participants' narratives from open-ended questions were tape-recorded, transcribed verbatim and translated into English. All verbatim responses were read, tabulated and summarised. Illustrative quotes are provided to highlight the key themes identified.

\section{Ethical approval}

The legal age of medical consent is 16 years in Zimbabwe, and all participants provided written informed consent. Participants were provided with compensation for the cost of travel to the clinic and for their time. This study was approved by the institutional review boards of the University of Zimbabwe and the University of California San Francisco.

\section{Results}

In the study sample of 45 young women, the median age was 19 years. Participants had a median of 10 years of education, one lifetime partner (range 1-10), 73\% had a husband or regular partner, $53 \%$ were married and $47 \%$ had

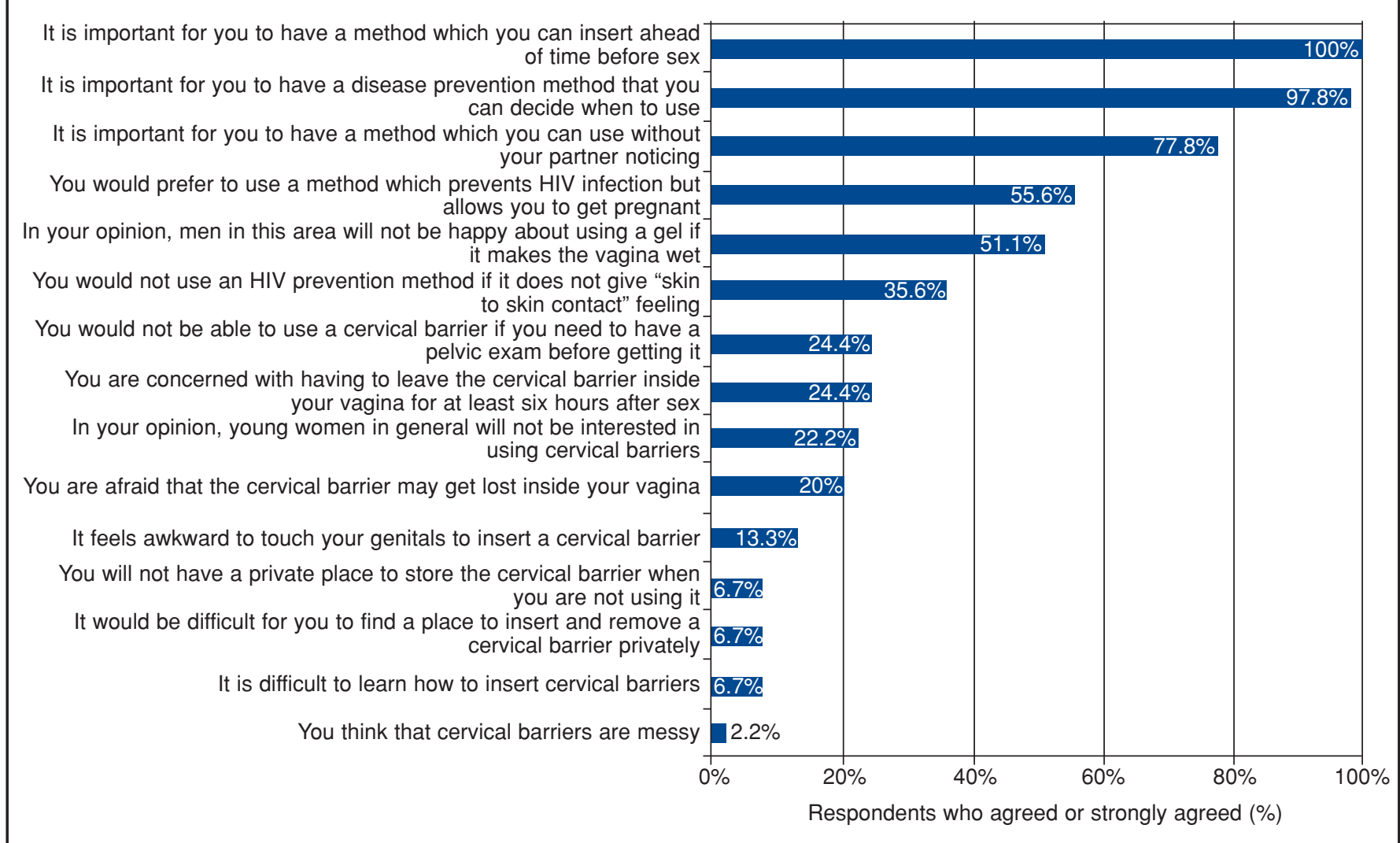

Figure 2 Study respondents' attitudes towards using a cervical barrier $(n=45)$. The figure shows the percentage of study respondents who "agreed" or "strongly agreed" with the statements in a 15-item cervical barrier attitude questionnaire 
Table 2 Participants' clinical experience and perceptions about cervical barrier use

\begin{tabular}{|c|c|c|c|c|}
\hline \multirow[t]{2}{*}{ Parameter } & \multirow[b]{2}{*}{$\begin{array}{l}\text { Total } \\
(n=45)\end{array}$} & \multicolumn{3}{|c|}{ Cervical barrier (CB) groups $[\%(n)]$} \\
\hline & & $\begin{array}{l}\text { SILCS } \\
(n=14)\end{array}$ & $\begin{array}{l}\text { Ortho All-Flex } \\
(n=15)\end{array}$ & $\begin{array}{l}\text { FemCap } \\
(n=16)\end{array}$ \\
\hline \multicolumn{5}{|l|}{ Number of attempts for successful device insertion } \\
\hline First attempt & $71.1(32)$ & 50.0 (7) & $80.0(12)$ & $81.3(13)$ \\
\hline Second attempt & $22.2(10)$ & 42.9 (6) & 20.0 (3) & $6.3(1)$ \\
\hline Third to fifth attempt & 6.6 (3) & 7.1 (1) & 0.0 & $12.6(2)$ \\
\hline \multicolumn{5}{|l|}{ Perceived ease of the insertion and removal process } \\
\hline \multicolumn{5}{|l|}{ Insertion was } \\
\hline Easy & $73.3(33)$ & $78.6(11)$ & $73.3(11)$ & $68.8(11)$ \\
\hline Somewhat difficult & $26.7(12)$ & 21.4 (3) & 26.7 (4) & $31.3(5)$ \\
\hline Very difficult & 0.0 & 0.0 & 0.0 & 0.0 \\
\hline \multicolumn{5}{|l|}{ Removal was } \\
\hline Easy & $84.4(38)$ & $100.0(14)$ & $86.7(13)$ & $68.8(11)$ \\
\hline Somewhat difficult & $15.6(7)$ & 0.0 & 13.3 (2) & $31.3(5)$ \\
\hline Very difficult & 0.0 & 0.0 & 0.0 & 0.0 \\
\hline Liked the device she tried & $93.3(42)$ & $100.0(14)$ & $93.3(14)$ & $87.5(14)$ \\
\hline \multicolumn{5}{|l|}{ Device participant wants to try in the future } \\
\hline SILCS ${ }^{\circledR}$ diaphragm & $57.8(26)$ & $51.7 \quad(8)$ & $60.0(9)$ & $56.3(9)$ \\
\hline Ortho All-Flex ${ }^{\circledR}$ diaphragm & $20.0(9)$ & 21.4 (3) & 33.3 (5) & $6.3(1)$ \\
\hline FemCap ${ }^{\mathrm{TM}}$ cervical cap & $22.2(10)$ & 21.4 (3) & 6.7 (1) & $35.7(6)$ \\
\hline \multicolumn{5}{|l|}{ Main (hypothetical) reason for wanting to use a CB } \\
\hline Mainly for pregnancy prevention & 4.4 (2) & 0.0 & 0.0 & 12.5 (2) \\
\hline Mainly for disease prevention & $28.9(13)$ & $35.7 \quad(5)$ & $26.7 \quad(4)$ & 25.0 (4) \\
\hline Mainly for both reasons & $66.7(30)$ & 64.3 (9) & 73.3 (11) & $62.5(10)$ \\
\hline \multicolumn{5}{|l|}{$\mathrm{CB}$ use preference } \\
\hline Prefers continuous use & $55.6(25)$ & 57.1 (8) & $46.7 \quad(7)$ & $62.5(10)$ \\
\hline & $44.4(20)$ & $42.9(6)$ & $53.3 \quad(8)$ & $37.5(6)$ \\
\hline \multicolumn{5}{|l|}{ Preference about using CB with gel } \\
\hline $\begin{array}{l}\text { Could use gel with a CB, even if she needs to use an applicator } \\
\text { to insert gel in the vagina }\end{array}$ & $82.2(37)$ & $71.4(10)$ & $86.7(13)$ & $87.5(14)$ \\
\hline Could use gel with a CB, but does not want to use an applicator & $15.6(7)$ & 21.4 (3) & $13.3 \quad(2)$ & $12.5(2)$ \\
\hline Prefer to use a CB without gel & $2.2(1)$ & 7.1 (1) & 0.0 & 0.0 \\
\hline
\end{tabular}

sex regularly. Other demographic information is summarised in Table 1. Only $13(29 \%)$ participants had heard of the diaphragm and none had used one. Two-thirds of participants reported having inserted some products intravaginally in the past year [including tampons, cotton wool or cloth $(64 \%)$, herbs $(7 \%)$, female condoms $(2 \%)$ or other item (2\%)] and $84 \%$ reported washing intravaginally with their finger.

\section{Clinical practice of $\mathrm{CB}$ insertion and removal}

All the participants practised $\mathrm{CB}$ insertion and removal Overall, $71 \%$ were able to correctly insert their assigned device at their first attempt, although more in the SILCS group required a second attempt (Table 2). All the participants but one (assigned to FemCap, and unable to remove her device herself) removed their device properly. The majority inserted $(n=31)$ and removed $(n=30)$ their device while squatting; the next most common position was with one foot on a chair or stool (data not shown). Overall, the majority thought that insertion or removal of their device was easy (73\% and $84 \%$, respectively). All those in the SILCS group said device removal was "easy", while a few participants in the other two groups reported some difficulty with removal. This was highlighted during participants' narratives, with four women in the FemCap group and one in the Ortho All-Flex group, reporting problems with insertion or removal of their device, because it was slippery, caused discomfort or could not be dislodged.

Staff specifically probed about participants' comfort level touching their genitals to insert the $\mathrm{CB}$, and the majority explained they were comfortable. Several women even referred to the familiar behavior of intravaginal washing during bathing. ["I did not feel any different from when I put my fingers during bathing. I did not feel pain or discomfort" (20 years old, divorced, Ortho All-Flex group)]. Women who reported intravaginal washing seemed more likely to find that insertion was easy (79\% vs $43 \%$ ). Conversely, in narratives about insertion experience, five women mentioned some discomfort or pain with touching their genitals, and six $(13 \%)$ agreed with the attitudinal statement: "It feels awkward to touch your genitals to insert a cervical barrier” (Figure 2).

\section{Device and use preferences, and attitudes towards using a $\mathrm{CB}$}

Some $93 \%$ of participants said they liked the device they tried (Table 2) and all participants said they were interested in participating in a CB study in the future. When asked which device they would like to try in the future, over half in the SILCS group and about a third in the Ortho All-Flex and FemCap groups chose the device they had tried. Over half the participants in the Ortho All-Flex and FemCap groups also chose SILCS (Table 2). Reasons given for this choice included finding SILCS (from the practice or from its appearance) easy to insert and remove due to its contoured design and finger groove, or finding it aesthetically pleasing.

Over half $(56 \%)$ the participants said they would prefer to use a $\mathrm{CB}$ continuously (removing it only once a day for washing) compared to episodic use (during sex only). Those who preferred continuous use mentioned several reasons: (a) they liked to "be prepared" if sex happens ["Wearing it all the time means you are always ready when your husband comes and he wants sex" (21 years old, married, FemCap group)]; (b) they wanted to be "protected" at all times ["Because sometimes you do not expect to have sex with someone, so that way you prevent many things" (16 years old, single, FemCap group)]; (c) they found continuous use easier/more convenient ["It is easier that way. Wearing it and then taking it off is not convenient" (19 years old, married, Ortho All-Flex group)] and (d) they could wear it "quietly" without their partner's 
knowledge ["I can prevent infection and pregnancy, and if my husband does not want I can use it until I decide to get pregnant. I liked the fact that my husband cannot tell it's there if he does not like it. Also it does not hurt me if I wear it all the time" (21 years old, married, SILCS group)]. Conversely, those who preferred episodic use invoked disliking "wearing it all the time" or concerns about the effect on the body of keeping the CB for a long time in situ ["I would also want to find out how my body will tolerate/take it before I can use it continuously" (17 years old, married, FemCap group)]. They also mentioned not being used to the device, worries about possible discomfort or that it may move out of place. Finally, many just said they liked to use the device only when needed ["Because it's only when you are having sex that you are at risk of infection" (20 years old, married, Ortho All-Flex group)]. One participant mentioned that the device would "last longer" if it is worn episodically.

Participants only experienced using gel on the rim of their devices to ease insertion. They were asked their hypothetical preference regarding use of gel with $\mathrm{CB}$ after it was explained to them that to afford maximum protection $\mathrm{CB}$ are normally used in conjunction with a gel (i.e. a spermicide for contraception), though the precise mode of application varies between device manufacturers. As shown in Table 2, the majority (82\%) said they could use gel with a $\mathrm{CB}$, even if it required using an applicator to insert gel in the vagina.

Overall, the participants' attitudes towards CB were favourable (Figure 2). Most participants favoured attributes associated with female control of the methods (such as providing the woman with decision-making power and allowing use without the partner noticing) as well as attributes associated with non-interference with sex (insertion ahead of time, and - to a lesser extent desire for a method that allows skin-to-skin contact). Of note, over half the participants agreed with the statements "men in this area will not be happy about using a gel if it makes the vagina wet" and "you would prefer to use a method which prevents HIV infection but allows you to get pregnant". Other attributes of CB that may represent a challenge for their acceptance and use included the requirement to have a pelvic examination prior to use (for the Ortho All-Flex diaphragm only), the current clinical recommendation to leave the $\mathrm{CB}$ for at least 6 hours postcoitally before removal, and concerns that the device may get lost inside the vagina; these were perceived as unfavourable by a fifth to a quarter of the participants. Fewer than $7 \%$ of the participants had concerns about privacy for insertion or storage, or learning the skills required to use $\mathrm{CB}$. Only one participant agreed with the statement that $\mathrm{CB}$ were messy.

\section{Dual protection}

As shown in Table, 1 , just over $50 \%(n=23)$ of the participants currently used effective hormonal contraception, while almost a third used no method. Only a quarter of the women reported using condoms every time they had sex. This highlighted substantial vulnerability for both pregnancy and HIV acquisition. Indeed, over twothirds of the women said they were "very worried" about getting pregnant, and even more (84\%) were "very worried" about getting infected with HIV. When asked what would be their main reason for using a $\mathrm{CB}$, the majority $(67 \%)$ said it was to protect both from pregnancy and disease, while almost a third said it would be mainly for disease prevention and two participants said for pregnancy prevention only (Table 2).

\section{Discussion}

The main objectives of this study were to assess the feasibility of conducting a larger CB study among vulnerable young women for contraception and/or for disease prevention (when used in combination with a microbicide) and to identify a promising candidate among three existing $\mathrm{CB}$ devices for such future study. The concept of $\mathrm{CB}$, and initial insertion experience, were well accepted in this selected, small group of diaphragm-naïve Zimbabwean young women. Further evaluation of these methods clearly appears feasible in this setting: all the participants were willing to try their assigned $\mathrm{CB}$ at the clinic, most liked their device and were comfortable with insertion and removal, finding the process easy. All said they were interested in participating in a future CB study, with just over half in the SILCS group and more than a third in each of the other two CB groups expressing interest in trying their assigned device again. A majority of women in all three groups said they wanted to try SILCS in the future. A (hypothetical) preference for SILCS was also revealed in the FGDs that were conducted prior to the device practice visit. ${ }^{39}$ This preference may have been carried over from the FGDs, although not all FGDs had a majority of participants preferring SICLS. In another acceptability study among sexually active monogamous couples, SILCS was preferred over Ortho All-Flex. ${ }^{31}$ It was noteworthy that only half of all SILCS users in the present study were able to successfully insert the device on the first attempt. Nevertheless, over three-quarters reported that SILCS insertion was "easy" and the participants" narratives did not reveal any information on this issue. Still, this matter is of concern and should be investigated further, as outside of a clinical study, those who fail at the first attempt may not be sufficiently motivated to try again. A previous study of the FemCap also noted difficulties with removal of the device, despite the removal strap, as was reported by those who tried this device here. ${ }^{40} \mathrm{~A}$ large proportion of the study participants had experience with intravaginal finger or product insertion, and intravaginal washing experience was associated with finding the $\mathrm{CB}$ insertion process easy. Other populations where intravaginal practice is not so prevalent may find the insertion process of $\mathrm{CB}$ more awkward and daunting. ${ }^{41}$

Whilst the manufacturer of the Ortho All-Flex diaphragm recommends application of gel only to the cervical side, other diaphragm variants and newer $\mathrm{CB}$ allow for the delivery of gel on both the cervical and vaginal side in one step, $10,40,42$ a feature that may be particularly relevant if $\mathrm{CB}$ are used with microbicides for disease prevention. Participants were comfortable with the idea of using gel on the cervical and vaginal side of the $\mathrm{CB}$, even if this required use of an applicator. However, this question was asked hypothetically, as volunteers had only used a limited amount of gel on the rim of their devices to ease insertion. In this study we chose to focus our assessment of the three devices separately from gel to avoid confounding the acceptability of one with the other. Ease of gel application with each device, insertion and removal of the devices when loaded with gel, and willingness to use gel, especially when having sex, will have to be empirically assessed with the use of a combination product. While here, more than half the participants thought men wouldn't like to have sex if gel made the vagina "wet", in user-based microbicide and diaphragm studies, gel in moderate amount was generally well accepted and liked by women and their male partners. ${ }^{43-45}$

Most participants favoured CB methods' attributes associated with female-control and non-interference with 
sex, which is consistent with results of other studies of female-controlled methods of HIV and pregnancy prevention. ${ }^{46-48}$ Overall attitudes towards CB were positive, and few potential barriers to use were noted. Among those, a frequently reported misconception about losing the device in the vagina ${ }^{41,46}$ was mentioned by a fifth of the sample. This could be easily addressed by educating women about correct female reproductive anatomy. About a quarter of the participants reported to be unwilling to receive pelvic examinations. Conveniently, new single-size CB such as SILCS and BufferGel Duet ${ }^{\circledR}, 42$ or FemCap which comes in three sizes, do not require clinician fitting. About a quarter of the participants were also concerned about the recommended waiting time until device removal. Of note, for the diaphragm, the clinical recommendation is to wait 6 hours after sex; however, the recommended removal time varies for different devices, it is not evidence-based, and should perhaps be empirically reassessed. 10,49

There are several limitations to this study. First, the sample was small. While our findings would have been more robust if all subjects had tried all three devices, funding limitations precluded multiple visits, and we were concerned that participants would be physically uncomfortable if we asked them to insert three different devices in one single session. Also, post-practice evaluations were conducted at the clinic by study staff; this may have led to socially desirable responses and overly positive reports about the devices tried.

The potential of $\mathrm{CB}$ as a dual-purpose method was important for most participants. However, simultaneously, the majority of participants agreed they wanted a HIVprevention method that also allowed conception. This was a sample of young women, many were nulliparous, and few were likely to have achieved their desired family size. Clearly both options are needed for women, as some will want dual protection while others will only want to be protected from disease. CB do not offer a disease prevention only option, but may satisfy unmet needs for dual-protection methods, when combined with a contraceptive gel that is also microbicidal. For those individuals wanting to conceive, other disease prevention methods should be developed, as condoms are the only proven methods currently available, and they will prevent both pregnancy and disease.

In summary, based on the present results, it should be feasible to conduct a user acceptability study of CB among vulnerable young women in Zimbabwe, to explore the dual-purpose potential of $\mathrm{CB}$ by assessing them in combination with a contraceptive and potential microbicide gel agent. In view of the diminished power in sexual relationships experienced by adolescent women in subSaharan Africa, dual-purpose women-initiated methods could be particularly relevant to this group.

\section{Statements on funding and competing interests}

Funding The study was funded by the University of California San Francisco (UCSF) AIDS Research Institute (ARI) Pilot Awards Program.

Competing interests None identified. Most of the work for this study was conducted while Dr van der Straten, Dr Sahin-Hodoglugil and Ms Clouse were based at the Department of OBGYN and Reproductive Sciences, University of California, San Francisco, CA, USA.

\section{References}

1 Joint United Nations Programme on HIV/AIDS (UNAIDS)/World Health Organization (WHO). AIDS Epidemic Update: December 2006. Geneva, Switzerland: UNAIDS/WHO, 2006.

2 Laga M, Schartlender B, Pisani E, Sow PS, Carael M. To stem HIV in Africa, prevent transmission to young women. AIDS 2001; 15: 931-934.
3 Gregson S, Nyamukapa CA, Garnett GP, Mason PR, Zhuwau $\mathrm{T}$, Carael M, et al. Sexual mixing patterns and sex-differentials in teenage exposure to HIV infection in rural Zimbabwe. Lancet. 2002; 359: 1896-1903.

4 Pettifor AE, Measham DM, Rees HV, Padian NS. Sexual power and HIV risk, South Africa. Emerg Infect Dis 2004; 10: 1996-2004

5 Stein ZA. HIV prevention: the need for methods women can use. Am J Public Health 1990; 80: 460-462.

6 Central Statistical Office (CSO) (Zimbabwe), Macro International Inc. Zimbabwe Demographic and Health Survey 2005-2006. Calverton, MD: CSO and Macro International Inc., 2007.

7 Johnson B, Ndhlovu S, Farr S, Chipato T. Reducing unplanned pregnancy and abortion in Zimbabwe through postabortion contraception. Stud Fam Plann 2002; 33: 195-202.

8 Cates W, Stewart F. Vaginal barriers: the female condom, diaphragm, contraceptive sponge, cervical cap, Lea's Shield and Femcap (Chapter 18). In: Hatcher RA, Trussell J, Stewart FH, Nelson AL, Cates W Jr, Guest F, et al. (eds), Contraceptive Technology (18th edn), New York, NY: Ardent Media, 2004.

9 Warner L, Hatcher RA, Steiner MJ. Male condoms (Chapter 16). In: Hatcher RA, Trussell J, Stewart FH, Nelson AL, Cates W Jr, Guest F, et al. (eds), Contraceptive Technology (18th edn), New York, NY: Ardent Media, 2004.

10 Ellertson C, Burns M. Re-examining the role of cervical barrier devices. OUTLOOK 2003; 20(2): 1-8. http://www.path.org/files/ eol20 2.pdf [Accessed 11 September 2009].

11 Moench TR, Chipato T, Padian NS. Preventing disease by protecting the cervix: the unexplored promise of internal vaginal barrier devices. AIDS 2001; 15: 1595-1602.

12 Pudney J, Quayle AJ, Anderson DJ. Immunological microenvironments in the human vagina and cervix: mediators of cellular immunity are concentrated in the cervical transformation zone. Biol Reprod 2005; 73: 1253-1263.

13 Behets F, Van Damme K, Turner A, Rabenja N, Ravelomanana $\mathrm{N}$, Raharinivo $\mathrm{M}$, et al. Evidence-based planning of a randomized controlled trial on diaphragm use for prevention of sexually transmitted infections. Sex Transm Dis 2008; 35: 238-242.

14 Luchters S, Chersich MF, Jao I, Schroth A, Chidagaya S, Mandaliya K, et al. Acceptability of the diaphragm in Mombasa Kenya: a 6-month prospective study. Eur J Contracept Reprod Health Care 2007; 16: 1-9.

15 van der Straten A, Kang M, Posner SF, Kamba M, Chipato T, Padian NS. Predictors of diaphragm use as a potential sexually transmitted disease/HIV prevention method in Zimbabwe. Sex Transm Dis 2005; 32: 64-71.

16 van der Straten A, Napierala S, Cheng H, Mauck C, Depineres $\mathrm{T}$, Dhlakama $\mathrm{P}$, et al. A randomized controlled safety trial of the diaphragm and cellulose sulfate microbicide gel in sexually active women in Zimbabwe. Contraception 2007; 76: 389-399.

17 Jewell N, van der Straten A, Montgomery E, Rosenblum M, Padian N. Diaphragms and lubricant gel for prevention of HIV [Author Reply]. Lancet 2007; 370: 1823-1824.

18 Padian NS, van der Straten A, Ramjee G, Chipato T, de Bruyn $\mathrm{G}$, Blanchard $\mathrm{K}$, et al. Diaphragm and lubricant gel for prevention of HIV acquisition in southern African women: a randomised controlled trial. Lancet 2007; 370: 251-261.

19 Ramjee G, van der Straten A, Chipato T, de Bruyn G, Blanchard K, Shiboski S, et al. The diaphragm and lubricant gel for prevention of cervical sexually transmitted infections: results of a randomized controlled trial. PLoS One 2008; 3(10): e3488.

20 Padian NS, Buvé A, Balkus J, Serwadda D, Cates W Jr. Biomedical interventions to prevent HIV infection: evidence, challenges, and way forward. Lancet 2008; 372: 585-599.

21 Pretorius ES, Timbers K, Malamud D, Barnhart K. Magnetic resonance imaging to determine the distribution of a vagina gel: before, during, and after both simulated and real intercourse. Contraception 2002; 66: 443-451.

22 Mauck C, Callahan M, Weiner DH, Dominik R. A comparative study of the safety and efficacy of FemCap, a new vaginal barrier contraceptive, and the Ortho All-Flex diaphragm. The FemCap Investigators' Group. Contraception 1999; 60: 71-80.

23 Shihata AA. The FemCap: a new contraceptive choice. Eur J Contracept Reprod Health Care 1998; 3: 160-166.

24 Schwartz JL, Mauck CK, Rountree RW, Ballagh SA, Creinin MD, Kilbourne-Brook M. SILCS diaphragm: postcoital testing of a new single-size contraceptive diaphragm. Obstet Gynecol 2006; 107(4 Suppl.): 12S.

25 CONRAD. Contraceptive Effectiveness and Safety of the SILCS Diaphragm. http://clinicaltrials.gov/ct2/show/NCT 00578877?term=SILCS+contraceptive+effectiveness+study\& rank=1 [Accessed 11 September 2009].

26 Behets F, Turner A, Van Damme K, Rabenja N, Ravelomanana 
$\mathrm{N}$, Zeller $\mathrm{K}$, et al. Acceptability and feasibility of continuous diaphragm use among sex workers in Madagascar. Sex Transm Infect 2005; 81: 472-476.

27 Bukusi E, Sharma A, Njoroge B, Tevi- Bennisan C, Duerr A Cohen $\mathrm{C}$. Acceptability of the diaphragm among women in an ongoing sexually transmitted infection efficacy trial. Paper presented at the International Society for Sexually Transmitted Diseases Research (ISSTDR) 15th Biennial Conference, Ottawa, Canada, 27-30 July 2003.

28 Bulut A, Ortayli N, Ringheim K, Cottingham J, Farley TM, Peregoudov $\mathrm{A}$, et al. Assessing the acceptability, service delivery requirements, and use-effectiveness of the diaphragm in Colombia, Philippines, and Turkey. Contraception 2001; 63: 267-275.

29 Sharma A, Bukusi E, Posner S, Feldman D, Ngugi E, Cohen CR. Sex preparation and diaphragm acceptability in sex work in Nairobi, Kenya. Sex Health 2006; 3: 261-268.

30 Coffey PS, Kilbourne-Brook M, Austin G, Seamans Y, Cohen J. Short-term acceptability of the PATH Woman's Condom among couples at three sites. Contraception 2006; 73: 588-593.

31 Coffey PS, Kilbourne-Brook M, Brache V, Cochón L. Comparative acceptability of the SILCS and Ortho ALL-FLEX ${ }^{\circledR}$ diaphragms among couples in the Dominican Republic. Contraception 2008; 78: 418-423.

32 Hardy E, de Padua KS, Jimenez AL, Zaneveld LJ. Women's preferences for vaginal antimicrobial contraceptives. II. Preferred characteristics according to women's age and socioeconomic status. Contraception 1998; 58: 239-244.

33 Montandon M, Sahin-Hodoglugil N, Bukusi E, Agot K, Boland B, Cohen C. Sexuality, HIV risk and potential acceptability of involving adolescent girls in microbicide research in Kisumu, Kenya. Sex Health 2008; 5: 339-346.

34 Rosenthal SL, Cohen SS, Stanberry LR. Topical microbicides. Current status and research considerations for adolescent girls. Sex Transm Dis 1998; 25: 368-377.

35 Rupp RE, Rosenthal SL. Vaginal microbicides and teenagers. Curr Opin Obstet Gynecol 2003; 15: 371-375.

36 Sahin-Hodoglugil N, van der Straten A, Mtetwa S, Clouse K, Chirenje T, Nyambo V, et al. "AIDS is a body lotion": HIV risk and attitudes towards cervical barriers as a potential method of HIV prevention among young women in Zimbabwe. Poster presentation at the National HIV Prevention Conference, Atlanta, GA, USA, 2-5 December 2007

37 Bradford LJ, Beck KH. Development and validation of a condom self-efficacy scale for college students. J Am Coll Health 1991; 39: 219-225.

38 Harvey SM, Bird ST, Maher JE, Beckman LJ. Who continues using the diaphragm and who doesn't: implications for the acceptability of female-controlled HIV prevention methods. Womens Health Issues 2003; 13: 185-193.

39 Mtetwa S, Chirenje T, Nyambo V, Clouse K, Sahin-Hodoglugil $\mathrm{N}$, Chirenje M, et al. Feasibility and acceptability of cervical barriers among vulnerable youth in Africa. Poster presentation at the 3rd South African AIDS Conference, Durban, South Africa 5-8 June 2007.

40 Mauck CK, Weiner DH, Creinin MD, Archer DF, Schwartz JL, Pymar HC, et al. FemCap with removal strap: ease of removal, safety and acceptability. Contraception 2006; 73: 59-64.

41 Epstein LB, Sokal-Gutierrez K, Ivey SL, Raine T, Auerswald C. Adolescent experiences with the vaginal ring. $J$ Adolesc Health 2008; 43: 64-70.

42 Ballagh S, Brache V, Mauck C, Callahan M, Cochon L, Wheeless $A$, et al. A Phase 1 study of the functional performance, safety, and acceptability of the BufferGel Duet. Contraception 2007; 77: 130-137.

43 Montgomery CM. The role of partnership dynamics in determining the acceptability of condoms and microbicides. AIDS Care 2008; 20: 733-740.

44 Salter ML, Go VF, Celentano DD, Diener-West M, Nkhoma CM, Kumwenda N, et al. The role of men in women's acceptance of an intravaginal gel in a randomized clinical trial in Blantyre, Malawi: a qualitative and quantitative analysis. AIDS Care 2008; 7: 853-862.

45 van der Straten A, Moore J, Napierala S, Clouse K, Mauk C, Hammond $\mathrm{N}$, et al. Consistent use of a combination product versus a single product in a safety trial of the diaphragm and microbicide in Harare, Zimbabwe. Contraception 2008; 77: 435-443.

46 Buck J, Kang MS, van der Straten A, Khumalo-Sakutukwa G, Posner S, Padian N. Barrier method preferences and perceptions among Zimbabwean women and their partners. AIDS Behav 2005; 9: 415-422.

47 Okal J, Stadler J, Ombidi W, Jao I, Luchters S, Temmerman M, et al. Secrecy, disclosure and accidental discovery: perspectives of diaphragm users in Mombasa, Kenya. Cult Health Sex 2008; 10: 13-26.

48 Woodsong C, Alleman P. Sexual pleasure, gender power and microbicide acceptability in Zimbabwe and Malawi. AIDS Educ Prev 2008; 20: 171-187.

49 Stewart F. Vaginal barriers: the diaphragm, contraceptive sponge, cervical cap and female condom (Chapter 18). In: Hatcher RA, Trussell J, Stewart F, Willard JC, Stewart GK, Guest F, et al. (eds), Contraceptive Technology (17th edn). New York, NY: Ardent Media Inc., 1998.
The Whole Day Through. Patrick Gale. London, UK: Harper Collins, 2009. ISBN-13: 978-0-00730601-5. Price: £7.99. Pages: 237 (paperback)

This is a love story that is narrated as if it takes place spanning a day from morning till nightfall. Yet the actual story is spread out over months. The narrative gives the reader glimpses into the lives of the characters, starting with a scene in the morning and ending with nightfall.

The main characters, Laura and Ben, meet after a long time apart in a chance meeting at the hospital where Ben works. He is a genitourinary medicine (GUM) doctor while Laura has returned home to care for her ailing mother, Professor Jellico, an erstwhile expert virologist. Ben's brother, Bobby, is a young gay man with Down's syndrome. Ben's wife, Chloe, hovers on the fringe of the story yet seems to affect Ben, Bobby and Laura in different ways.

The story flows well and is an easy, light read. The passage of time from morning to nightfall wasn't obvious to me till I read the interview with the author at the end of the book which is very interesting indeed. The story covers important themes relating to sexual and reproductive health care. Some of the more important are the attitudes to sex and sexuality in people with learning disabilities and their right to sexual expression. At the other end of the spectrum the book looks at the ageing Professor Jellico and the impact of the physical effects of ageing on her quality of life - this in turn affects Laura who cares for her - thus illustrating children who care for their parents and how it can affect their lives, privacy, sexuality and relationships. Seemingly they are free to do as they please but cannot because of the position they find themselves in.

I found the book easy to read with simple themes and a believable story line. The author gave Ben the profession of a GUM doctor but I felt disappointed that this aspect of his role did not receive the weighting it could have. Perhaps the themes of homosexuality, HIV and GUM are intertwined in the story for the purpose of setting the platform for Ben's and Bobby's characters. In all, an enjoyable read!

Reviewed by Neelima Deshpande, MRCOG, MFSRH Staff Grade Doctor in Sexual and Reproductive Healthcare, Heart of Birmingham Teaching Primary Care Trust, Birmingham, UK

We hope that journal readers enjoyed reading The Whole Day Through, and also discovering whether their opinion of the book matched that of our guest reviewer. In the April 2010 issue, we there will be a trilogy of Swedish crime fiction books under scrutiny, namely The Girl With the Dragon Tattoo (538 pages, Maclehose Press/Quercus, 2008, ISBN-13: 978-1-84724-545-8, £7.99), The Girl Who Played With Fire (608 pages, Maclehose Press/Quercus, 2009, ISBN-13: 978-1906694180, $£ 7.99$ ) and The Girl Who Kicked the Hornets' Nest (602 pages, Maclehose Press/Quercus, 2009, ISBN-13: 978-1906694166, £18.99) by Stieg Larsson. Keen readers out there had better make an early start on reading these books!

We want to remind journal readers that if they would like to offer to review an appropriate fiction title of their own choosing then they should contact the Journal Editorial Office by e-mail (journal@fsrh.org) in the first instance with details of their nominated title. 